\title{
RELATIVE VISIBILITY OF LUMINOUS FLASHES FROM NEON LAMPS AND FROM INCANDESCENT LAMPS WITH AND WITHOUT RED FILTERS
}

\author{
By F. Chapin Breckenridge and J. E. Nolan
}

\section{ABSTRACT}

The visibility of light derived from an incandescent lamp with a red filter has been tested in comparison with that of light from a neon lamp and also with that of a similar incandescent lamp without the filter. Especial attention was given to producing beams having similar candlepower distributions. The tests include a variety of clear, hazy, rainy, and foggy weathers and ranges up to $7 \mathrm{~km}$. The results indicate no advantage in the case of the neon lamp and a loss of visibility in all weathers from the use of the filter.

\section{CONTENTS}

Introduction

II. The beacon

III. Adjustments_._.

IV. The location and weather

V. Procedure

VI. Observations____ 18

VII. Discussion_._.

VIII. Conclusions.-.

IX. Acknowledgments.

\section{INTRODUCTION}

The development of commercial neon lamps led to experiments with such lamps as marine and aeronautical beacons. These experiments have been followed by frequent claims that the light from neon lamps has exceptional fog-penetrating properties, but no definite evidence was offered to support the claims. Contrary opinions followed in turn. Up to the present these service tests have led only to conflicting opinions regarding the fog-penetrating properties of the light from neon lamps. ${ }^{1}$

Very few tests definitely attempting comparison of the visibility of light from neon lamps with light from incandescent source lamps

1 H. N. Green, Artificial Light as an Aid to Aerial Navigation, Ill. Eng. (London), 20, pp. 101 and 133; 1927. Also discussion following. 
with color filters have been reported. Porter $^{2}$ found that a neon induction lamp seemed at equal candlepowers to have slightly better fog penetration than a clear incandescent lamp or even an incandescent lamp with red color filter, but he also states that the advantage of the neon lamp, if there is any, is due more to color contrast, longer observation period, and greater beam spread than to any marked ability of the neon light to penetrate fog. On the other hand, Foulke concluded, apparently from the same and additional tests, that the neon beacon is superior to the incandescent lamp beacon.

Found and Forney ${ }^{3}$ have reported that observations made in foggy weather have shown that it is possible to pick up the neon light before any of the other lights in the same vicinity are observed.

The experiments described in this paper were designed to determine definitely, under controlled conditions, whether the light from a neon lamp becomes visible at greater distances, or remains visible to greater distances, than light from an incandescent lamp with a color filter when the color, shape, and brightness of the source, the angular distributions of intensity in the beam, and the weather conditions are the same in both cases. As a matter of additional interest, the effect of the color filter upon the visibility of a clear beam was also determined. In general, the method was to observe flashing signals from an experimental beacon from various distances and under various weather conditions. Nearly all the observations were made at night, and a photometric wedge was used for most of them.

\section{THE BEACON}

The experimental beacon was designed to produce three rotating beams which will be referred to as the neon beam, the red beam, and the clear beam. The neon and red beams were made as closely alike as was possible with such different sources, in order that any characteristics peculiar to the light from neon lamps might be clearly differentiated from other effects. The clear beam was designed to duplicate the beam which was obtained if the filter was removed from the unit producing the red beam. The inclusion of the clear beam also made it possible to tell whether it was the neon or the red flash which was being seen when only one of them was visible.

Figure 1 shows diagrammatically the optical parts of the beacon designed to produce the three beams. $T$ is a turntable on which the revolving parts are mounted. $L$ is a plano-convex lens $140 \mathrm{~mm}$ in focal length and $110 \mathrm{~mm}$ in diameter. $A$ is a circular aperture 15 $\mathrm{mm}$ in diameter in the plane of the principal focus of ' $L$. A piece of

\footnotetext{
${ }_{2}$ Discussion on The Present Status of Aeronautical Lighting in the United States, by L. C. Porter, Trans. I. E. S., 22, p. 1003; 1927. See p. 1019 for discussion by T. E. Foulke and p. 1009 for statement by W. T. Harding.

8 C. G. Found and J. D. Forney, Hot Cathode Neon Arcs, Trans. A. I. E, E., 47, p. 747; 1928.
} 


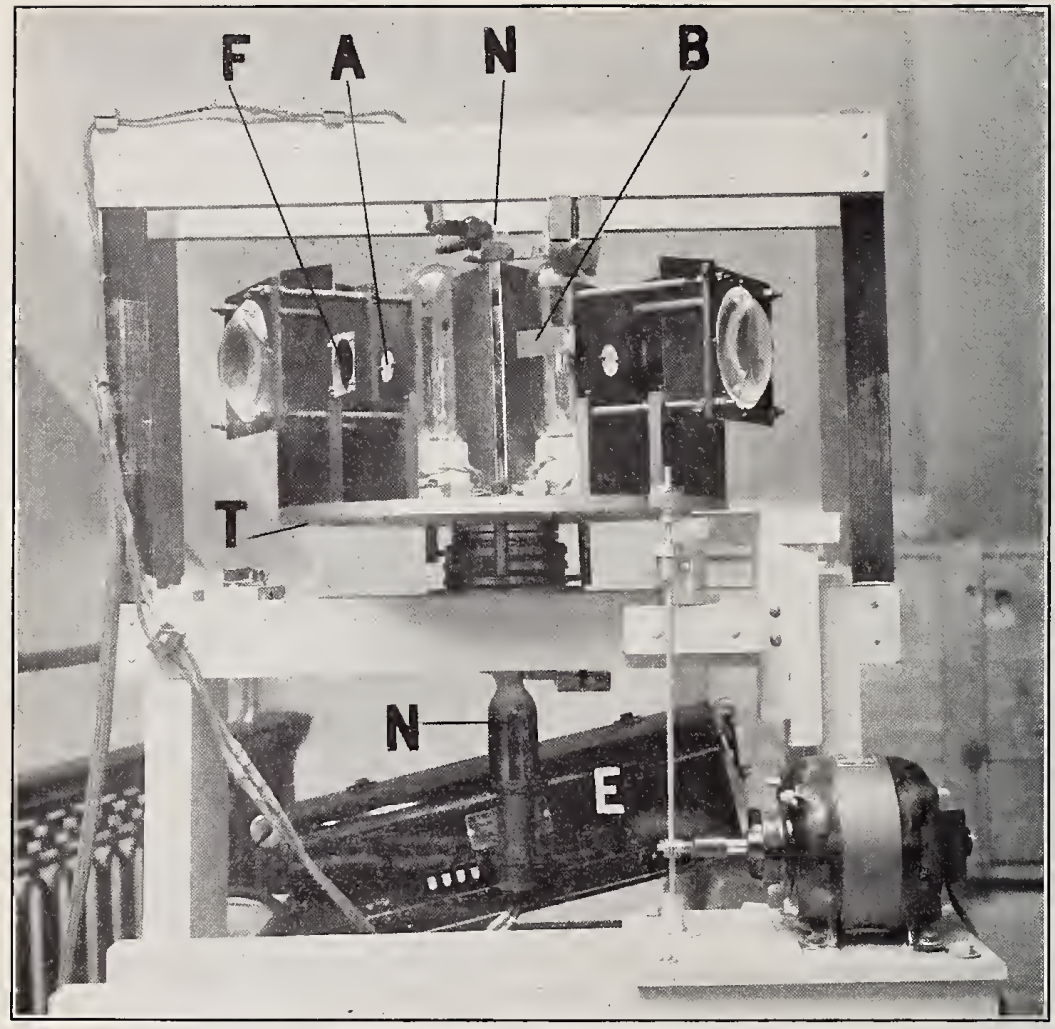

Figure 2.-Beacon with some of the stray light shields removed

$A$, aperature with ground glass in place; $B$, brass plate with fiducial lines for setting lamp at its corrcet position; $E$, cquipment for starting the neon lamp; $F$, filter opening with filter removed; $N$, neon lamp; $T$, turntable.

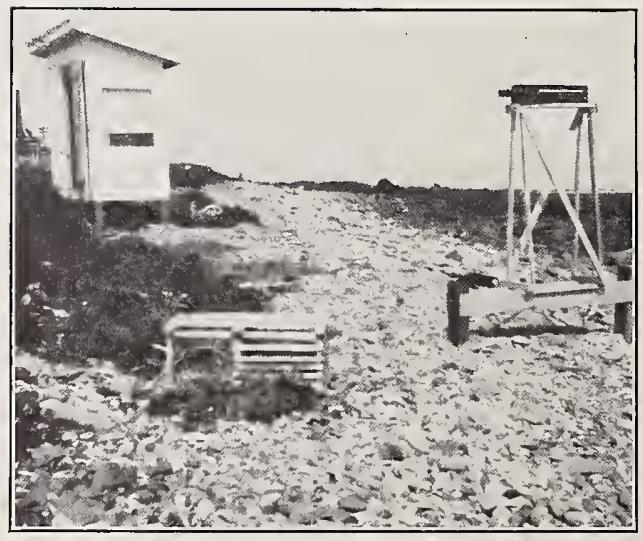

FIGURE 3.-Beacon house with photometer in place for measuring intensity distribution of beacon beams 
ground glass, $G$, covers this aperture in the red and clear units. $N$ is the neon lamp which does not revolve but projects through the hole $H$ at the center of the turntable. $I$ is a 1,000 -watt, 115 -volt, incandescent lamp. $F$ is the red glass filter.

Figure 2 is a photograph of the assembled beacon with some of the stray light shields removed. The parts are indicated as in Figure 1.



FIgURE 1.-Diagrammatic plan view of experimental beacon. $R, N$, and $C$ are red, neon, and clear units, respectively

$A$, A perture; $F$, fllter of red glass; $G$, ground glass; $H$, hole in turntable; $I$, incandescent lamp; $L$, lens; $N$, neon lamp; $S$, shields for cutting off stray light, additional shields were used around the units and around the edge of the turntable; $T$, turntable. The arrow shows direction of rotation.

The clear unit is identical with the red unit except for the red filter and the metal plate to hold it. No ground glass was used in the neon unit, the aperture being placed as close to the neon lamp as practicable.

The neon lamp used is a hot-cathode, alternating-current lamp. The luminous part of the lamp is a tube $2.5 \mathrm{~cm}$ in diameter and $47 \mathrm{~cm}$ in length. Only the small portion of this length back of the aperture was used. The diameter of the tube was not large enough to make 
the aperture uniformly luminous from all angles. When viewed from the center of the lens, the entire aperture appeared luminous. From the edge of the lens at either side a small part of the aperture appeared dark. As no larger neon tubes of sufficient brightness were available, and as the aperture was as close as practicable to the neon tube, this difficulty could be overcome only by making the aperture smaller, which would have reduced the flash length as well. The curves of horizontal candlepower distribution indicated no serious difference between the neon beam and the red beam. It was thought better to tolerate the small difference in horizontal distribution rather than a shorter flash.

The maximum candlepowers of both the neon and red beams were of the order of 175 to 190 candles. The clear beam showed a maximum of approximately 730 candles. The beacon revolved seven times a minute, giving an interval between flashes of about 3 seconds. The flash length is estimated as 0.2 second.

The neon lamp required a special transformer and starting device. It was maintained at constant candlepower by controlling the primary current to the transformer. An ammeter was used to measure the current. By a suitable arrangement of switches it was possible to take the ammeter out of the neon lamp circuit and place it in series with either of the incandescent lamps without interrupting the current in the neon lamp.

The other details of the beacon's construction are plainly shown in Figure 2.

\section{ADJUSTMENTS}

The similarity of the optical systems assured apparent sources of the same shape and size with similar horizontal candlepower distributions. By moving the lamps closer to or away from the ground glass it was possible to vary the intensities in the beams with very little effect on the relative shape of the horizontal distributions.

The red glass filter, a piece of Corning "lighthouse red" glass ground to a thickness of $2.15 \mathrm{~mm}$, was selected to give an approximate color match. By varying the color temperature of the incandescent lamp in the red unit a very good color match was obtained at about 65 volts. The color temperature of the lamp in the clear unit was adjusted to match that of the lamp (filter removed) of the red unit. The adjustments for color-match were made before adjusting the position of the lamps back of the ground glass. The clear unit was adjusted to duplicate as closely as possible the beam given by the red unit when the red filter was removed.

The original adjustments for color match and equality of intensity were made at the bureau, using a Bechstein rotating sector photometer. A Sharp-Millar photometer was included in the field equipment, and a special stand was built in front of the beacon house to support 
this photometer. The foundation for this stand was firmly set in the ground, but the stand itself was always removed when visibility observations were to be made, so that there was no possibility of obstructing the view of the beacon. Figure 3 shows the beacon house with the photometer on its stand. With this equipment satisfactory candlepower distribution curves were obtained during the test.

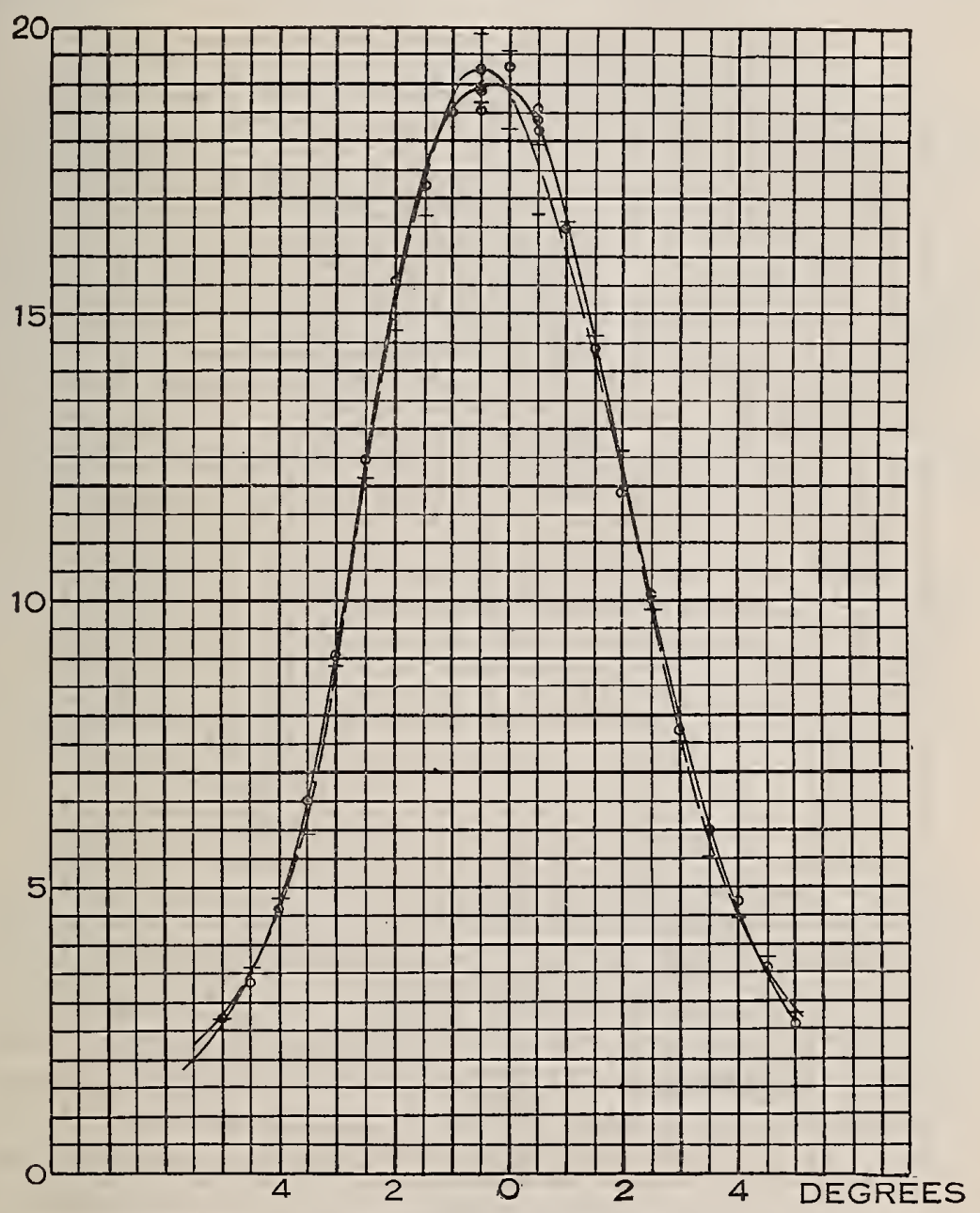

FIGURE 4.-Intensity distribution of the neon and red beams

Full line, with circles, red beam; broken line with crosses, neon beam. Ordinates show relative values in arbitrary units.

When first assembled in the field, the incandescent lamps were set by means of special lamp sights, the bulbs having fiducial lines etched upon them. One of these sights is shown at $B$ in Figure 2. A gage was used to reset the neon lamp at the correct distance back of its aperture. This original set-up was later checked by taking distribu$53811^{\circ}-29-2$ 
tion curves with the Sharp-Millar photometer and was found satisfactory. Twice the neon lamp failed and had to be replaced by a new one. Each time this was done the currents were readjusted to equalize the horizontal distributions. These changes amounted to less than 3.5 per cent and did not affect the color temperature seriously. After the readjustment a complete new set of distribution curves

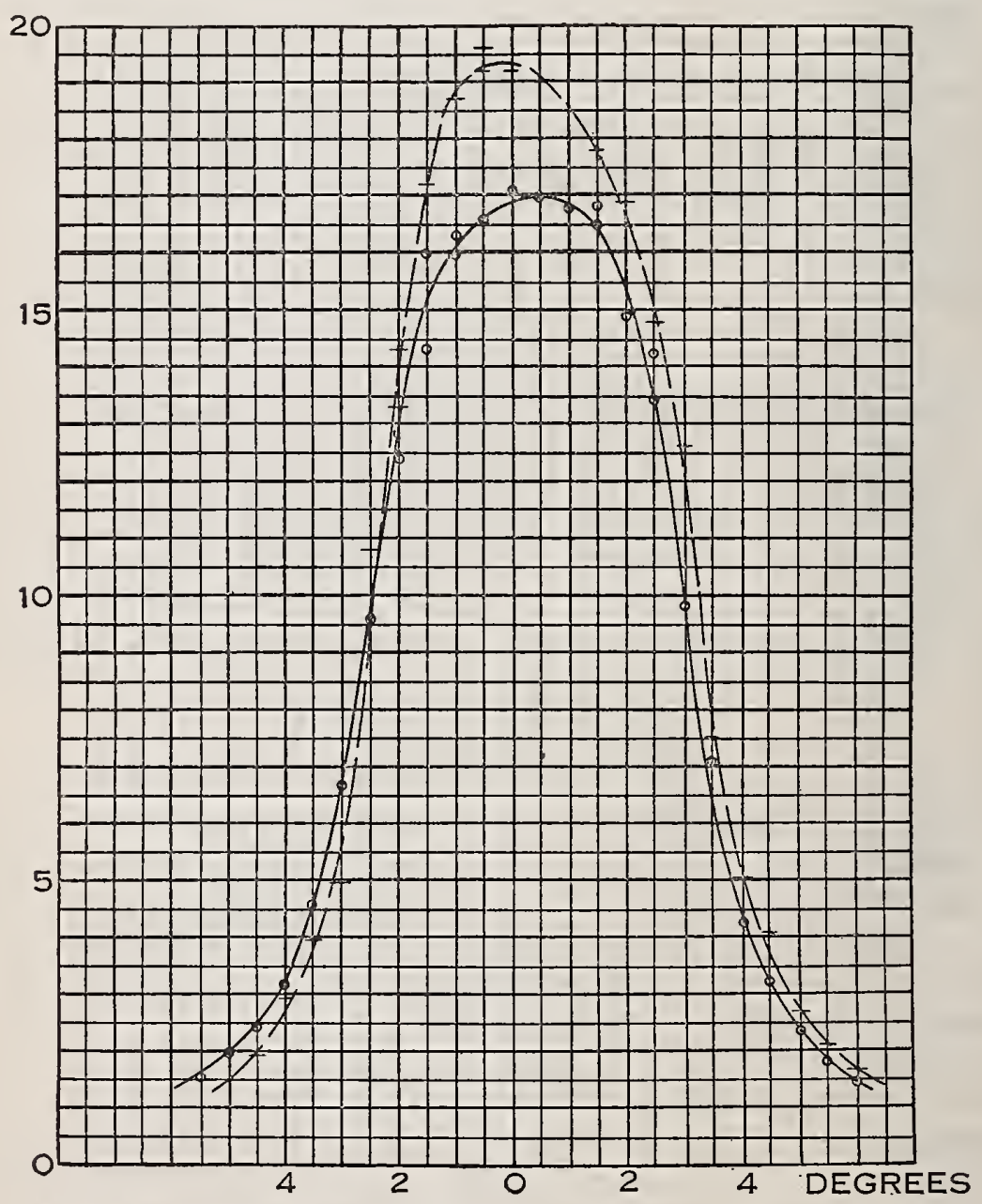

FIGURE 5.-Intensity distribution of the clear beams and the beam from the red unit with the filter removed

Full line with circles, beam from red unit; broken line with crosses, clear beam.

was made each time. A final set of distribution curves has been made since the apparatus was returned to the bureau, the lamps being again reset by lamp sights and gage.

Figures 4 and 5 reproduce the horizontal candlepower distribution curves taken September 22. The neon and red curves show one of 
the closest agreements obtained on any of the calibrations of the red and neon units. The curves for the clear beam and the beam from the red unit with filter removed show one of the poorest agreements obtained on any of the runs for adjusting the clear beam. Taken together, they give a typical idea of the agreement obtained throughout the test.

\section{THEE LOCATION AND WEATHER}

The beacon was erected at Moody Point, Me., on the rocks immediately north of Ogunquit Beach. This location afforded a continuous view of the beacon along the beach for $4 \mathrm{~km}$ ( 2.5 miles) southward and frequent views of it along the coast eastward from Ogunquit to Bald Head Cliff, a maximum range of $7 \mathrm{~km}$ (4.35 miles). The fog signal records of the Bureau of Lighthouses indicate that this stretch of coast offers as high a probability of frequent fogs as any suitable location on the North Atlantic coast.

Thirty-three series of observations were made during the months of August and September, 1928. The weather during these runs has been classified as follows:

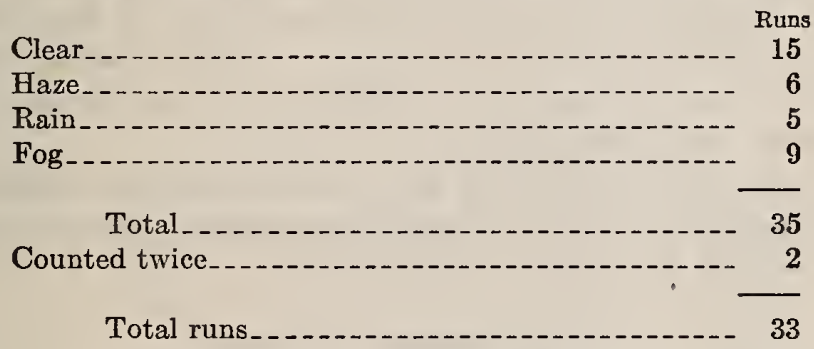

Most of the fogs varied in intensity during the observations, and three of them cleared away so suddenly that the observations were not convincing. In these cases, before the observer was able to get to the limit of visibility, the fog suddenly lifted, allowing insufficient time for any satisfactory observations. There were other fogs which occurred on nights when no neon lamp was available or cleared away before observations could be started. One of the runs classified as fog was made in daylight.

\section{PROCEDURE}

The method of taking observations had to be varied somewhat with the weather. Generally, observations were made from five stations, designated by their distance from the beacon, as follows:

$7,000 \mathrm{~m}$ ( 4.35 miles) station

$5,700 \mathrm{~m}$ (3.54 miles) station

$4,750 \mathrm{~m}$ (2.95 miles) station

$4,000 \mathrm{~m}$ (2.49 miles) station

$1,910 \mathrm{~m}$ (1.19 miles) station 
The three more distant stations were located on the rocky shore between Ogunquit and Bald Head Cliff. The other two stations were located on the beach south of the beacon.

Except for some of the earlier observations, a photometric wedge was used in clear and hazy weather. This wedge, which was obtained from the Eastman Kodak Co., was of the gelatin filter type. It was mounted in a metal case having holes spaced $1 \mathrm{~cm}$ apart along the length of the wedge in such a manner that the observer could hold one of the holes in front of his eye while watching the beacon, thereby introducing a definite part of the wedge into the path of the light. The holes are designated by consecutive numbers, 1 being the hole having the highest transmission, about 86 per cent. The ratio of transmission from hole to hole was approximately 55 per cent. The procedure was to determine and record at each observation station the highest numbered hole on the wedge through which the observer could see each type of flash consistently. When the haze was heavy enough to reduce the maximum range of visibility to less than $4 \mathrm{~km}$ (2.5 miles), the observer sought to find the distance at which each type of flash was just visible. The transmission of a hazy atmospherc varies so rapidly, however, that this could not be done for all the flashes beforc conditions would change. It was, however, frequently possible to find a distance at which some of the flashes would be visible while others were not.

In taking the observations, the writers generally alternated from night to night, one man taking the observations, the other attending the beacon and controlling the currents.

\section{OBSERVATIONS}

The observations taken with the photometric wcdge are given in Tables 1 and 2. The larger the wcdge reading the brighter the flash appeared. A plus sign indicates that the flash was quite readily visible through the hole corresponding to that number but was not consistently seen through the next hole. The symbol "V" means visible to the naked eye but not through hole 1 of the wedge. " $N$ " means not visible but known to be operating. A blank space means no observation was taken. The observations have been grouped according to observers on account of the considerable difference in visual sensitivity between the observers, which causes the readings in Table 2 to average higher than those in Table 1. 
TABLE 1.-Wedge observations by F.C.B.

\begin{tabular}{|c|c|c|c|c|c|c|c|c|c|c|c|c|c|c|c|c|}
\hline \multirow{2}{*}{ Run No. } & \multicolumn{3}{|c|}{$7,000 \mathrm{~m}$} & \multicolumn{3}{|c|}{$5,700 \mathrm{~m}$} & \multicolumn{3}{|c|}{$4,750 \mathrm{~m}$} & \multicolumn{3}{|c|}{$4,000 \mathrm{~m}$} & \multicolumn{3}{|c|}{$1,910 \mathrm{~m}$} & \multirow{2}{*}{ Weather } \\
\hline & 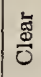 & $\stackrel{q}{\mathcal{D}}$ & $\begin{array}{l}\text { 명 } \\
\text { ㄱ }\end{array}$ & 苐 & 足 & $\begin{array}{l}\text { I } \\
\stackrel{8}{4} \\
\text { 乙 }\end{array}$ & $\frac{\stackrel{s}{\rightleftarrows}}{0}$ & 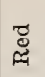 & $\begin{array}{l}0 \\
8 \\
8 \\
z\end{array}$ &  & 巴્ટ & 兽 & $\frac{\mathfrak{d}}{0}$ & 鸪 & $\begin{array}{l}\text { D } \\
8 \\
\stackrel{0}{Z} \\
2\end{array}$ & \\
\hline $\begin{array}{l}12 \\
14 \\
16 \\
20\end{array}$ & $\begin{array}{l}3 \\
3 \\
1 \\
1 \\
6\end{array}$ & $\begin{array}{l}2 \\
2 \\
2\end{array}$ & $\begin{array}{l}2 \\
2\end{array}$ & $\begin{array}{l}4 \\
3 \\
3 \\
1+ \\
6\end{array}$ & $\begin{array}{l}3 \\
2 \\
2 \\
1 \\
3\end{array}$ & $\begin{array}{l}3 \\
2 \\
2 \\
1 \\
3\end{array}$ & $\begin{array}{l}4+ \\
4 \\
5 \\
5 \\
7\end{array}$ & $\begin{array}{l}3+ \\
3 \\
3 \\
2 \\
3\end{array}$ & $\begin{array}{l}3 \\
3 \\
3 \\
2 \\
3 \\
3\end{array}$ & $\begin{array}{l}5 \\
5 \\
4 \\
5 \\
7\end{array}$ & $\begin{array}{l}4 \\
3 \\
3 \\
2 \\
4+\end{array}$ & \begin{tabular}{|l|}
4 \\
3 \\
3 \\
2 \\
$4+$
\end{tabular} & $\begin{array}{l}9 \\
7 \\
5 \\
6\end{array}$ & $\begin{array}{l}5+ \\
4 \\
3 \\
4\end{array}$ & $\begin{array}{l}5 \\
4 \\
3 \\
4\end{array}$ & $\begin{array}{l}\text { Clear. } \\
\text { Do. } \\
\text { Do. } \\
\text { Light fog. } \\
\text { Clear. }\end{array}$ \\
\hline $\begin{array}{l}22 \\
24 \\
26 \\
26 \\
28 \\
30 \\
30 \\
\ldots\end{array}$ & $\begin{array}{l}3 \\
5 \\
4 \\
4\end{array}$ & $\begin{array}{l}2 \\
1 \\
2 \\
1+\end{array}$ & $\begin{array}{l}2 \\
1 \\
2 \\
1\end{array}$ & $\begin{array}{l}4 \\
3 \\
6 \\
3 \\
5\end{array}$ & $\begin{array}{l}2 \\
2+ \\
2 \\
1 \\
1\end{array}$ & $\begin{array}{l}2 \\
2 \\
2 \\
1\end{array}$ & $\begin{array}{l}6 \\
4 \\
7 \\
4 \\
6\end{array}$ & $\begin{array}{l}2 \\
2 \\
3 \\
1 \\
1\end{array}$ & $\begin{array}{l}2 \\
2 \\
3 \\
1\end{array}$ & $\begin{array}{l}7 \\
5 \\
6 \\
3 \\
4\end{array}$ & $\begin{array}{l}3 \\
3+ \\
3 \\
V \\
V\end{array}$ & $\begin{array}{l}3 \\
3 \\
2 \\
\mathrm{~V}\end{array}$ & $\begin{array}{l}7 \\
9 \\
9 \\
7\end{array}$ & $\begin{array}{l}4 \\
5 \\
5 \\
3\end{array}$ & $\begin{array}{l}4 \\
5 \\
5 \\
3\end{array}$ & $\begin{array}{l}\text { Do. } \\
\text { Light haze. } \\
\text { Clear. } \\
\text { Rain and heavy haze. } \\
\text { Hazy. }\end{array}$ \\
\hline
\end{tabular}

Larger numbers indicate higher apparent hrightness.

$\mathrm{V}=$ visihle to the naked eye hut not through hole 1 of the wedge.

$+=$ not reduced to the limit of visihility at the hole recorded, hut not consistently visihle through the next hole.

Blank space $=$ no ohservations taken.

TABLE 2.-Wedge observations by J. E. N.

\begin{tabular}{|c|c|c|c|c|c|c|c|c|c|c|c|c|c|c|c|c|}
\hline \multirow[b]{2}{*}{ Run No. } & \multicolumn{3}{|c|}{$7,000 \mathrm{~m}$} & \multicolumn{3}{|c|}{$5,700 \mathrm{~m}$} & \multicolumn{3}{|c|}{$4,750 \mathrm{~m}$} & \multicolumn{3}{|c|}{$4,000 \mathrm{~m}$} & \multicolumn{3}{|c|}{$1,910 \mathrm{~m}$} & \multirow[b]{2}{*}{ Weather } \\
\hline & $\begin{array}{l}4 \\
0 \\
0 \\
0\end{array}$ & 胥 & $\begin{array}{l}\text { a } \\
8 \\
\stackrel{8}{4} \\
\end{array}$ & $\stackrel{\breve{g}}{\stackrel{\Phi}{0}}$ & 总 & $\begin{array}{l}\text { 몽 } \\
0 \\
\text { ㄱ }\end{array}$ & $\frac{\breve{\Xi}}{0}$ & 葆 & $\begin{array}{l}\text { D } \\
8 \\
\overline{8}\end{array}$ & $\stackrel{\text { 氖 }}{\stackrel{\Phi}{0}}$ & 总 & $\begin{array}{l}7 \\
8 \\
\Phi \\
7\end{array}$ & $\stackrel{d}{\mathbb{\Xi}}$ & 总 & 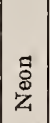 & \\
\hline $\begin{array}{l}13-\ldots \ldots \\
15-\ldots . \\
19 \\
21-\ldots-. \\
23 \ldots\end{array}$ & $\begin{array}{l}5 \\
4 \\
2 \\
5\end{array}$ & $\begin{array}{l}4 \\
3 \\
2 \\
4\end{array}$ & $\begin{array}{l}4 \\
3 \\
2 \\
4\end{array}$ & $\begin{array}{l}6 \\
5 \\
4+ \\
6 \\
5+\end{array}$ & $\begin{array}{l}5 \\
4 \\
3 \\
5 \\
4+\end{array}$ & $\begin{array}{l}5 \\
4 \\
3 \\
5 \\
4\end{array}$ & $\begin{array}{l}6 \\
6 \\
5 \\
5 \\
8\end{array}$ & $\begin{array}{l}4+ \\
4+ \\
4 \\
4 \\
5\end{array}$ & $\begin{array}{l}4+ \\
4+ \\
4 \\
4 \\
5\end{array}$ & $\begin{array}{l}6+ \\
5+ \\
6 \\
6 \\
8\end{array}$ & $\begin{array}{l}5 \\
4 \\
4 \\
5 \\
6\end{array}$ & $\begin{array}{l}5 \\
4 \\
4 \\
5 \\
6\end{array}$ & $\left|\begin{array}{c}9 \\
9 \\
9 \\
8+ \\
10\end{array}\right|$ & $\begin{array}{l}7 \\
6 \\
6 \\
6 \\
7\end{array}$ & \begin{tabular}{|l|}
$7+$ \\
6 \\
6 \\
6 \\
7
\end{tabular} & $\begin{array}{l}\text { Clear. } \\
\text { Slight haze. } \\
\text { Slight haze, clearing. } \\
\text { Clear. } \\
\text { Do. }\end{array}$ \\
\hline $\begin{array}{l}25 \\
27-- \\
29 \\
33 \\
\cdots\end{array}$ & $\begin{array}{l}4 \\
6 \\
6\end{array}$ & $\begin{array}{l}3 \\
3 \\
4\end{array}$ & $\begin{array}{l}3 \\
3 \\
4\end{array}$ & $\begin{array}{l}5 \\
7 \\
6 \\
7+\end{array}$ & $\begin{array}{l}4 \\
4+ \\
4 \\
5\end{array}$ & $\begin{array}{l}4 \\
4 \\
4 \\
5\end{array}$ & $\begin{array}{l}6+ \\
8 \\
8 \\
8\end{array}$ & $\begin{array}{l}5 \\
5 \\
5+ \\
5\end{array}$ & $\begin{array}{l}5 \\
5 \\
5+ \\
5\end{array}$ & $\begin{array}{l}7 \\
8+ \\
8 \\
8\end{array}$ & $\begin{array}{l}5+ \\
5+ \\
5 \\
5\end{array}$ & $\begin{array}{l}5+ \\
5+ \\
5 \\
5\end{array}$ & $\begin{array}{r}10 \\
9 \\
10 \\
10\end{array}$ & $\begin{array}{l}7 \\
6 \\
7 \\
7\end{array}$ & $\begin{array}{l}7 \\
6 \\
7 \\
7\end{array}$ & $\begin{array}{l}\text { Slight haze. } \\
\text { Clear. } \\
\text { Do. } \\
\text { Do. }\end{array}$ \\
\hline
\end{tabular}

Larger numbers indicate higher apparent hrightness.

$t=$ not reduced to the limit of visihility at the hole recorded hut not consistently visible through the next hole.

Blank space $=$ no observations taken.

Table 3 summarizes the observations taken on foggy nights when the wedge could be used at most only part of the time. These observations have been arranged in the order taken, so that progressive changes appear as successive observations. The movements of the observer toward and from the beacon can be followed by noting the changes in distance. The symbol " $\mathrm{P}$ " indicates that the flashes, previously invisible, are picked up. "L" indicates that the 
flashes previously visible are lost from sight. "I" means intermittently visible. Additional details are given in the following notes:

TABLE 3.-Observations through fog

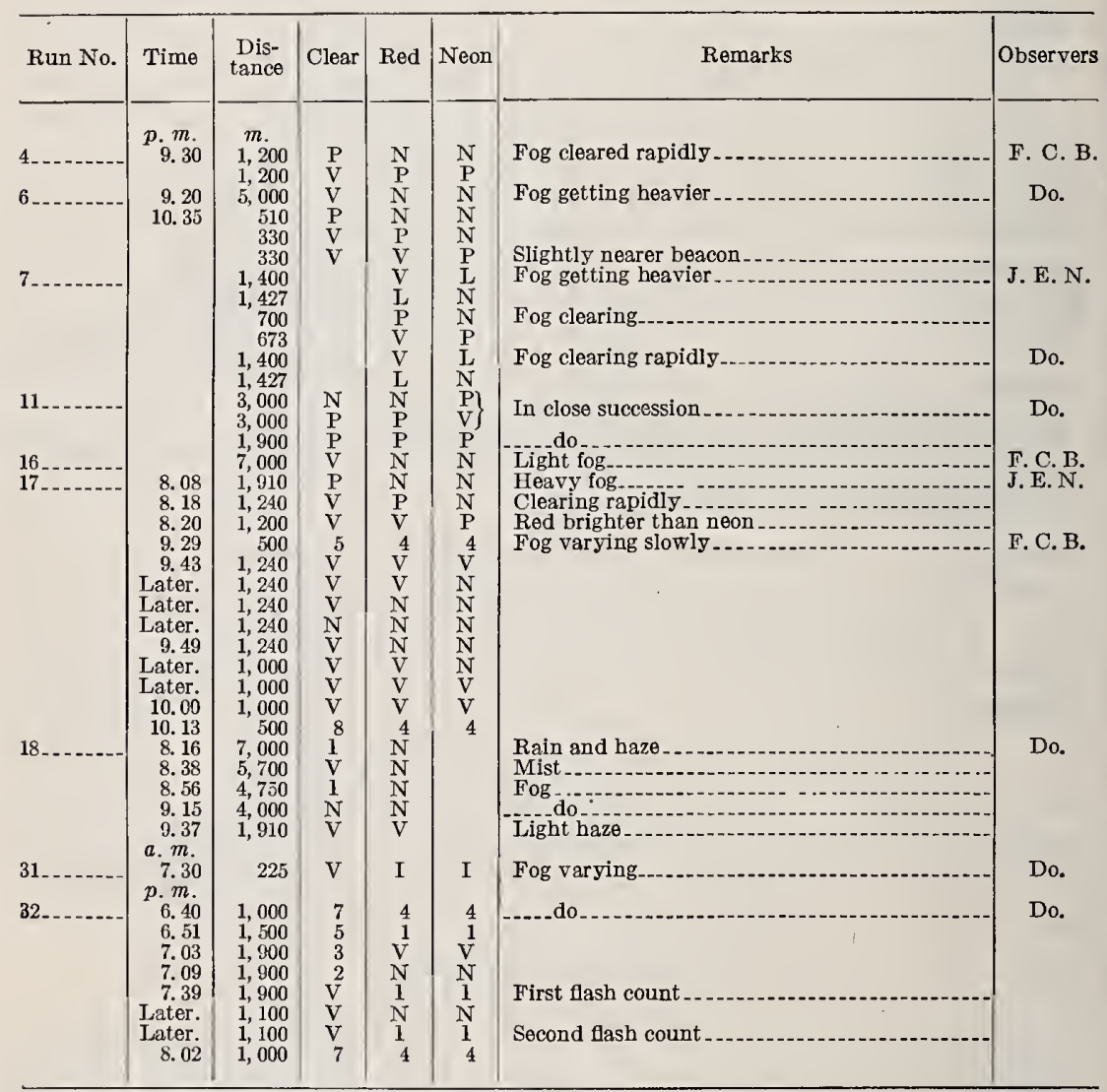

Larger numbers indicate higher apparent brightness.

I =intermittently visible.

$\mathrm{L}=$ lost from sight.

$\mathrm{N}=$ not visible.

$\mathrm{P}=$ picked up.

$\mathrm{V}=$ visible to naked eye but not through hole 1.

Blank space $=$ no observations taken.

\section{NOTES}

Run No. 4.-The fog cleared so rapidly that about 45 seconds after the first gleam was detected all three flashes were clearly visible.

Run No. 6.-The increasing density of the fog obscured the beacon after the observations at $5,000 \mathrm{~m}$ (3.1 miles), so that no flashes were seen thereafter until the observer was only $510 \mathrm{~m}$ (560 yards) from the beacon. The neon flash was seen very soon after the red flash.

Run No. \%.-The line voltage dropped below normal during this run, making it impossible to operate all three units. The clear unit was not operated, and the neon unit frequently dropped to half its normal current. For this reason the results of this run are not conclusive. 
Run No. 11-This is the only case in which the neon flash was picked up before the others. The fog cleared rapidly, and other flashes were seen immediately after the neon flash. The picking up of the neon flash first was probably a matter of chance.

Run No. 16.-At shorter distances the wedge was used; the observations are found in Table 1.

Run No. 1\%.-During the observations by J. E. N. the neon current was unsteady, dropping so low at times that the lamp went out. During the observations by F. C. B. the current was steadier.

Run No. 31.-The short range obtained was due to the daylight, which made it necessary to see the flashes against a background of illuminated fog. The red and neon flashes were each missed at times, apparently one as often as the other.

Run No. 32.-During the first flash count, which included about 40 cycles, 10 red flashes and 7 neon flashes were missed. The second flash count included 19 cycles; the only flash missed was the second red flash.

There were five runs made in rain or mist. None of these observations are significant in respect to the neon lamp. For the first three $(2,3$, and 11$)$ the wedge was not available, and during both the other runs (18 and 28) the neon lamp failed. Runs 2 and 3 are not included in the tables because none of the flashes were ever obscured. The observations furnish no definite proof that rain did not affect the clear and red flashes alike, but it was noted in the reports for runs 2 , 3 , and 11 that the clear flash did not appear as much brighter than the red flash as usual. Such observations are merely impressions and are not, of course, conclusive.

\section{DISCUSSION}

The selectivity of the wedge used for the visibility observations has been determined for light of the three types used. For the red and neon lights the ratio of the transmission for the neon light to that for the red light remained between 0.98 and 1.04. This selectivity is not large enough to warrant a correction in view of the order of precision obtainable in making the observations.

The transmission of the wedge for the light of the clear and red beams has also been determined. These values showed an increasing selectivity for the higher readings on the wedge exceeding 15 per cent at hole 6 . It was not feasible to measure the selectivity beyond hole 6 because the transmission was so low, but the transmission values have been extrapolated to cover all that portion of the wedge used in taking the visibility observations.

Having determined the transmission of the wedge for the light of the clear and red beams, respectively, it was possible to express the wedge observations given in Tables 1 and 2 for these beams as wedge transmission values and then in each case to form the ratio of the transmission value for the clear beam to that for the red beam. These ratios are given in Tables 4 and 5 . 
Since the clear beam was of higher intensity than the red beam, it is natural that lower wedge transmission could be used without obscuring the clear flashes. Had atmospheric effects offset the advantage of higher initial candlepower and conferred upon the red beam a greater visibility than that of the clear beam, then, under such conditions of weather and distance, the clear beam would require higher wedge transmissions than the red beam, and the ratios given in Tables 4 and 5 would exceed 1.00. We find, however, only one case in each table in which the ratio was equal to 1.00 , while in all the other cases it is less. than 1.00 .

Figure 6 shows how the average wedge transmission ratio varied with distance for the visibility observations taken by each of the two

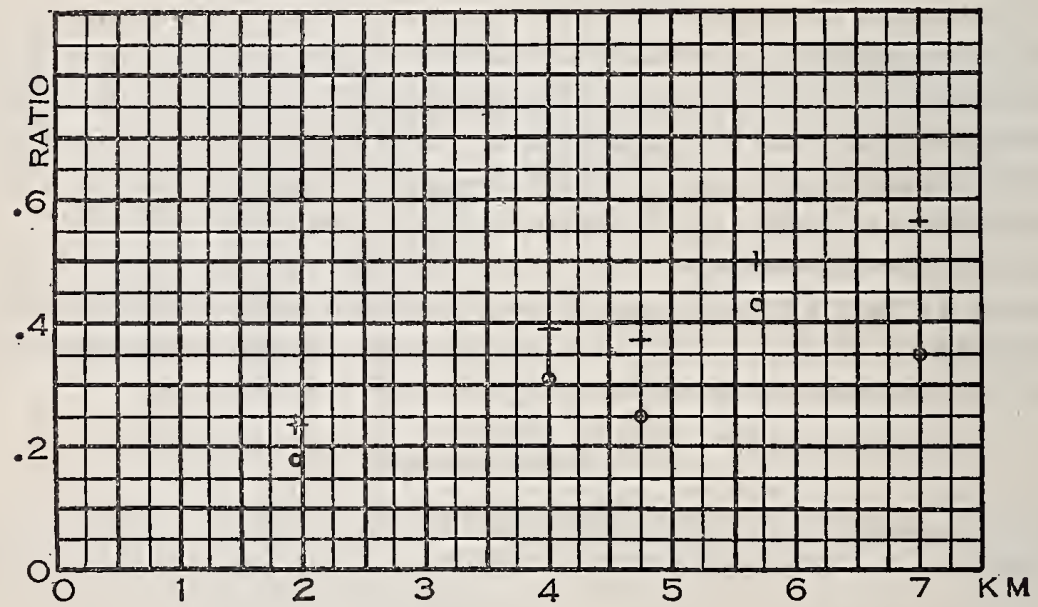

FIgURE 6.-Variation of the wedge transmission ratio with distance

The points plotted are the average of all those taken by each observer at each station; circles, observations by F. C. B.; crosses, observations by J. E. N.

observers. Since the results for each of the observers show the same systematic variation, it is assumed that this is not accidental. As the distance increases there is a tendency for the ratio to approach 1.00 ; that is, the visibility of the red beam approaches closer to that of the clear beam, a distance effect overcoming in part the advantage of the higher initial candlepower of the clear beam. In other words, there is a tendency for the energy in the clear beam to be reduced more rapidly than that in the red beam with increasing distance. Since the energy at the same wave length must be affected similarly in the two beams, this difference in transmission through the atmosphere must be due to the energy at the shorter wave lengths being lost from the clear beam more rapidly than that at the longer wave 
lengths. This is presumably due to selective scattering. Such selective scattering must cause some reddening of the clear beam. That such a reddening was not generally observed was probably due to the impossibility of seeing the clear beam at short and long ranges simultaneously.

At the beacon the red beam had approximately 0.25 times the luminous intensity of the clear beam. At $1,910 \mathrm{~m}$ from the beacon one observer's values show a mean wedge transmission ratio of 0.18 and the other observer's values a ratio of 0.23 . These low values may be due to Purkyne effect, the use of the wedge being virtually a comparison of brightnesses at a very low level with a consequent loss of sensitivity in the red region.

Turning to Tables 4 and 5, we do not find that there is any tendency for the values taken in foggy or hazy weather to rise above the means of all the values taken at their respective distances by the same observer, as should be the case if the red beam possesses superior fogpenetrating properties. This suggests that the shortening of the visible range of lights in fog is due to nonselective scattering, absorption, and the fact that the fog forms a luminous background affording less contrast to the light under observation. These effects are independent of the color of the light and are presumably due to particles of larger size than those which cause the selective absorption referred to above as a distance effect.

TABLE 4.-Ratio of wedge transmission for clear beam to that for red beam $\left(T_{C} / T_{R}\right)$, as indicated by observations in Table 1

\begin{tabular}{|c|c|c|c|c|c|c|}
\hline Run No. & $7,000 \mathrm{~m}$ & $5,700 \mathrm{~m}$ & $4,750 \mathrm{~m}$ & $4,000 \mathrm{~m}$ & $1,910 \mathrm{~m}$ & Weather \\
\hline $\begin{array}{l}12-14 \\
14 \\
16 \\
20\end{array}$ & $\begin{array}{r}0.58 \\
.58 \\
.10\end{array}$ & $\begin{array}{r}0.60 \\
.58 \\
.58 \\
1.00- \\
.18\end{array}$ & $\begin{array}{l}0.60 \\
.60 \\
.33 \\
.17 \\
.10\end{array}$ & $\begin{array}{l}0.61 \\
.33 \\
.60 \\
.17 \\
.18+\end{array}$ & $\begin{array}{l}0.10+ \\
.18 \\
.33 \\
.34\end{array}$ & \multirow{3}{*}{$\begin{array}{l}\text { Clear. } \\
\text { Do. } \\
\text { Do. } \\
\text { Light fog. } \\
\text { Clear. } \\
\text { Do. } \\
\text { Light haze. } \\
\text { Clear. } \\
\text { Rain and haze. } \\
\text { Haze. }\end{array}$} \\
\hline $\begin{array}{l}22 \ldots \\
24 \ldots \ldots \\
26 \ldots \\
28 \\
30 \ldots\end{array}$ & $\begin{array}{l}.58 \\
.09 \\
.32 \\
.17+\end{array}$ & $\begin{array}{l}.32 \\
.58+ \\
.10 \\
.31 \\
.09\end{array}$ & $\begin{array}{l}.10 \\
.32 \\
.10 \\
.17 \\
.05\end{array}$ & $\begin{array}{l}.10 \\
.33+ \\
.18\end{array}$ & $\begin{array}{l}.18 \\
.10 \\
.10 \\
.10\end{array}$ & \\
\hline Mean & .35 & .43 & .25 & .31 & .18 & \\
\hline
\end{tabular}

$T_{C}$ and $T_{R}$-wedge transmission for clear and red beams, respectively. + indicates values given are somewhat too small. S See Note below. Blank space=observations incomplete.

Note.-These symbols have been used because the corresponding observations in Table 1 indicato probable values in between two adjacent holes of the wedge. 
TABLE 5.-Ratio of wedge transmission for clear beam to that for red beam $\left(T_{C} / T_{R}\right)$, as indicated by observations in Table 2

\begin{tabular}{|c|c|c|c|c|c|c|}
\hline Run No. & $7,000 \mathrm{~m}$ & $5,700 \mathrm{~m}$ & $4,750 \mathrm{~m}$ & $4,000 \mathrm{~m}$ & $1,910 \mathrm{~m}$ & Weather \\
\hline $\begin{array}{l}13-15 \\
15 \\
191 \\
23\end{array}$ & $\begin{array}{r}0.61 \\
.60 \\
1.00 \\
.61\end{array}$ & $\begin{array}{l}0.63 \\
.61 \\
.60- \\
.63 \\
.61\end{array}$ & $\begin{array}{l}0.34+ \\
.34+ \\
.61 \\
.61 \\
.19\end{array}$ & $\begin{array}{l}0.63 \\
.61- \\
.34 \\
.63 \\
.35\end{array}$ & $\begin{array}{r}0.36 \\
.19 \\
.19 \\
.35 \\
.20\end{array}$ & \multirow{3}{*}{$\begin{array}{l}\text { Clear. } \\
\text { Slight haze. } \\
\text { Do. } \\
\text { Clear. } \\
\text { Do. } \\
\text { Slight haze. } \\
\text { Clear. } \\
\text { Do. } \\
\text { Do. }\end{array}$} \\
\hline $\begin{array}{l}25 \\
27 \\
29 \\
33\end{array}$ & $\begin{array}{l}.60 \\
.18 \\
.34\end{array}$ & $\begin{array}{l}.61 \\
.18+ \\
.34 \\
.34-\end{array}$ & $\begin{array}{l}.63- \\
.19 \\
.19+ \\
.19\end{array}$ & $\begin{array}{l}.34+ \\
.19 \\
.19 \\
.19\end{array}$ & $\begin{array}{l}.20 \\
.19 \\
.20 \\
.20\end{array}$ & \\
\hline Mean & .56 & .50 & .37 & .39 & .23 & \\
\hline
\end{tabular}

$T_{C}$ and $T_{R}$-wedge transmission for clear and red beams, respectively.

+ indicates values given are somewhat too small. indicates values given are somewhat too large. Sote below.

Blank space $=$ no observations taken.

Nore.-These symbols have been used because the corresponding observations in Table 2 indicate probable values in between two adjacent holes of the wedge.

Of all the wedge observations taken only one can be interpreted as indicating greater visibility for the neon flash, and this is found in run 13 (Table 2 ) at the $1,910 \mathrm{~m}$ station. In this instance a plus sign was used for the neon flash but not for the red flash, indicating that the neon flash appeared brighter to the observer through the seventh hole of the wedge than did the red flash. Against this single case there are six instances in which the red flash seemed stronger than the neon flash in Table 1 and two instances in Table 2. The total comparisons of neon and red in Table 1 are 42 and 43 in Table 2 . The wedge observations, therefore, indicate no advantage in visibility for the light from the neon lamp.

The observations made with the unaided eye, in general, show a slight advantage for the red beam. The only advantage indicated for the neon beam appears in run 32 , in which the number of missed flashes was found to be about 50 per cent greater for the red beam than for the neon beam. As both sets of flashes were near the limit of visiblity so that only a small change in apparent brightness would cause a flash to be missed and as the number of observations is small so that an accidental variation is probable, this result does not indicate any marked difference in visibility.

\section{CONCLUSION}

We conclude that there is no difference, sufficiently great to be found by the methods of this test, between the visibility of light from a neon lamp and light of the same color and horizontal candlepower distribution from an incandescent lamp.

With regard to the comparison of the clear and red beams, the results of the test admit of no doubt. The addition of the red filter 
does not increase the range of a clear beam under any weather conditions. It was, however, noticed that the red and neon flashes were generally easier to find among the shore lights, especially before the observers had learned just where to look for the beacon.

These conclusions applied to the problem of beacon design suggest that the neon lamp must be compared with the combination of incandescent lamp and color filter entirely on the basis of performance at the beacon. First of all, we must have a neon lamp which has a sufficiently high brightness to make possible a satisfactorily high intensity without using reflectors of impractical size. Second, the lamp and such auxiliary apparatus as is necessary inust be reliable and inexpensive to maintain. If a neon lamp can be produced satisfying both these requirements, it will merit consideration upon the basis of efficiency alone, and in this respect it seems likely that the neon lamp will stand superior to the combination of incandescent lamp and filter.

In localities where competing lights are not common the use of incandescent lamps without filter makes possible longer distances between beacons. It seems probable that in regions where airway beacons must be seen against a backgound thickly set with other lights the loss of range which is caused by the use of a red filter is more than compensated by the greater facility with which the red flashes can be picked up.

\section{ACKNOWLEDGMENTS}

It is a pleasure to acknowledge the many kindly and valuable suggestions received from Dr. J. Franklin Meyer both during the course of the experimental work and in connection with the preparation of this report. Thanks are also due to E. G. Anderson for determining transmission values for the wedge, to I. G. Priest and Dr. K. S. Gibson for the loan of calibrated filters and for helpful suggestions.

Washington, December, 1928. 